\title{
Towards an Integrated Methodological Framework for Understanding Embodiment in $\mathrm{HCl}$
}

Anna Xambó

Institute of Education

23-29 Emerald Street

London, WC1N 3QS

a.xambo@ioe.ac.uk

Carey Jewitt

Institute of Education 23-29 Emerald Street

London, WC1N 3QS

c.jewitt@ioe.ac.uk

Sara Price

Institute of Education 23-29 Emerald Street

London, WC1N 3QS

s.price@ioe.ac.uk

\begin{abstract}
The third wave in $\mathrm{HCI}$ reveals how embodiment matters in post-WIMP computing systems. Yet it is still unclear what methods provide effective insight into the nature of embodiment in $\mathrm{HCI}$ in relation to both design and use. This paper presents work in progress on MIDAS, a cross-disciplinary methodological research project on embodiment and technology exploring synergies across the fields of Digital Arts and Social Sciences. We argue that exploiting these synergies can contribute towards an integrated, innovative and progressive framework

for understanding digital body interactions. We introduce the 5 ongoing case studies that inform MIDAS, outline the project's use of multimodal ethnography, and discuss two emerging themes: 'conceptualising the body' and 'the sensory', which will contribute to a methodological framework for informing future design, analysis and evaluation of HCI systems.
\end{abstract}

\section{Author Keywords}

Methodological innovation; design futures;

embodiment; HCI methods; digital arts; social sciences

\section{ACM Classification Keywords}

CHI 2014, Apr 26-May 01 2014, Toronto, ON, Canada. ACM 978-1-4503-2474-8/14/04

http://dx.doi.org/10.1145/2559206.2581276
H.5.2. Information interfaces and presentation (e.g., HCI): User Interfaces - Theory and methods. 


\section{Introduction}

The 'third wave' in HCI reveals how embodiment matters in post-WIMP computing systems $[2,7,9]$ where the body is used differently compared to pointand-click interaction. It provides a different lens for understanding alternative computing systems to window-icon-mouse-pointer systems, such as ubiquitous, mobile, collaborative or social computing systems. This paradigm is referred by [7] as "situated perspectives", a sum of perspectives that studies HCI interaction as situated in a particular context and which connects to qualitative disciplines such as ethnography or practice-based research. An important challenge is to develop methodological approaches for understanding the complex nature of embodiment in $\mathrm{HCI}$, which can inform design, analysis and evaluation of this wide range of bodily interactions in situated contexts.

This paper introduces the Methodological Innovation in the Digital Arts and the Social Sciences (MIDAS) project, which aims to develop an innovative methodological framework capable of capturing a broader understanding of embodiment in $\mathrm{HCI}$. We believe this offers a comparative and integrated study of methods, which will contribute towards clarifying best methods for researching embodiment; developing new methods; and more broadly, contributing towards a unified strand on embodiment in HCI. The work presented here is based on a first phase of this project, and illustrates how emerging themes offer potential benefits to the $\mathrm{HCI}$ community.

\section{Our approach to embodiment}

To date there are numerous theoretical approaches to researching embodiment in $\mathrm{HCI}$, raising challenges of how to reach a consensus, and how to develop valuable methodological approaches in the context of HCI. As outlined by [13], theories of embodiment in $\mathrm{HCI}$ can be divided into two main strands: (i) embodied interaction and (ii) embodied cognition. Embodied interaction [5] focuses on tangible and social computing as examples of post-WIMP systems (e.g., interactive tabletops or mobile devices). This strand is concerned with the phenomenological aspects of HCI. For example, how meaning is dynamically built in relation to situated action in the world [5]. Embodied cognition, instead, refers to perspectives that rethink the Cartesian view of cognition. For example, the role of the environment related to the situated body and mind [8], or the role of physical experience related to abstract concepts [12]. Our position is to integrate both major strands of embodiment in HCI by developing an integrated framework centered on the interrelations between the body, the digital, and methods.

\section{Our methodological approach}

This project draws on multimodality and ethnography to investigate methodologies in situated encounters to produce a multimodal ethnographic framework [10, 11]. MIDAS examines methods used to research notions of embodiment through an exploration of 5 ethnographic case studies ( 3 in Digital Arts and 2 in Social Science), which are research centres and labs, over one year. Through ethnographic observation, we aim to get a sense of the methods and practices used in each research site related to the body and the digital. We use fieldnotes, photographs, and video recordings to document these routine methodological practices. Data analysis consists of iteratively identifying themes related to the 3 main areas of body, digital and methods across sites through reviewing the 


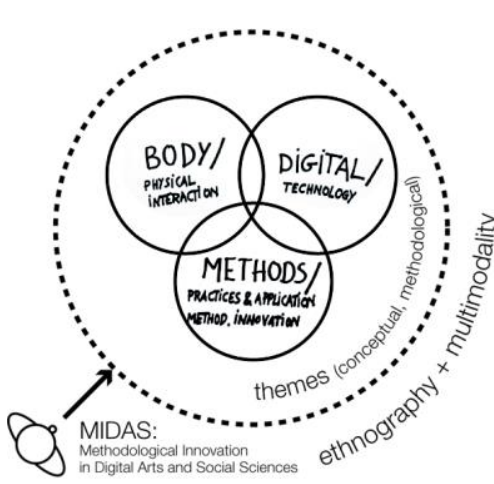

Figure 1. MIDAS methodological approach to researching embodiment. collected material (Figure 1). The selected themes appear to resonate across at least one digital arts site and one social science site with the potential to be points of synergy and connection or dissonance. Themes can be classified as conceptual and methodological. In the following 3 sections we first present the 5 case studies, and then introduce 2 initial conceptual themes: 'conceptualising the body' and 'the sensory'.

\section{Case studies}

Each case study has been selected on the basis of being a hub of methodological innovation, each offering differently focused conceptions of the body, and engaged in the everyday use of digital technologies. The first stage of the project focuses on understanding what and how methods are used in the sites at an institutional and group level (Table 1 ), which represent a third of the data we plan to collect. Next stages are focusing on understanding in-depth individuals' practices.

The Centre for Contemporary and Digital Performance (CCDP), Brunel University, examines the exchange of knowledge between research, particularly bodycentered physical research, and creation in artistic performance. CCDP works with methods inspired by aesthetic and neuro-aesthetic approaches to

embodiment [3]. This brings ideas and methods from philosophy that interrogate the nature of the body and digital technologies and their interface, and ideas of performance as research, which is relevant to MIDAS.

The Fashion Digital Studio (FDS), at London College of Fashion (LCF), University of the Arts London, is a multidisciplinary centre for technology and innovation in fashion. This site focuses on 'Digital Transformations' to investigate new physical-to-digital interfaces. This digital focus on the body - often seen in a fragmented unfamiliar way - combined with a contemporary interest in materiality explore, enhance and challenge a range of corporeal senses and sensations that are helpful in making strange the body within MIDAS [1].

The Information Experience Design Programme (IED), at the Royal College of Art, investigates the way people construct, access and interpret information in the physical world, augmented environments and digital systems. IED works at the boundaries of design and research [14], playing with ideas of the body, context and technologies. It works with an eclectic mix of methods grounded in art-based Making as Research. The intense focus on visuality and the physicality of interaction and research is of interest to MIDAS.

The London Knowledge Lab (LKL), at the Institute of Education (IOE), is an inter-disciplinary research centre concerned with how communication, learning and interaction are re-mediated by digital technologies. We focus on a project on embodiment and learning through whole body interaction, examining how a multimodal approach can provide insight into embodied forms of learning. The ways in which the project is envisaging the whole body in space and linking the physical and the cognitive is of interest to MIDAS.

The Cognition, Genes and Developmental Variability lab (CoGDeV) is part of Institute of Education's Department of Psychology and Human Development. The research interests of the lab relate to cognitive development in neurodevelopmental disorder groups, with a specific emphasis on visuo-spatial cognition. The group works 


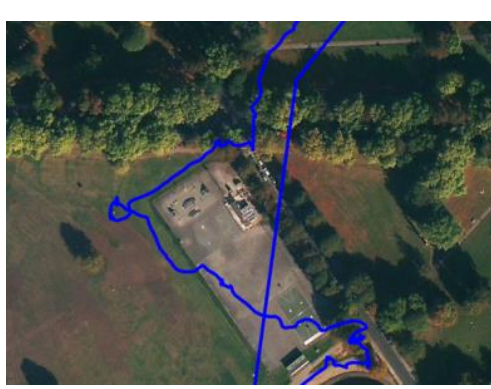

Figure 2. The body: third-person view on a 2D digital map.

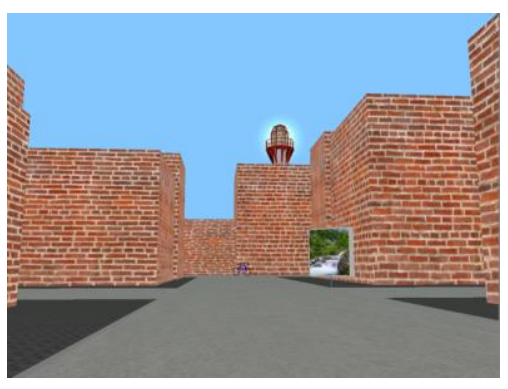

Figure 3. The body: first-person view in a 3D maze, (CELSTRAD.

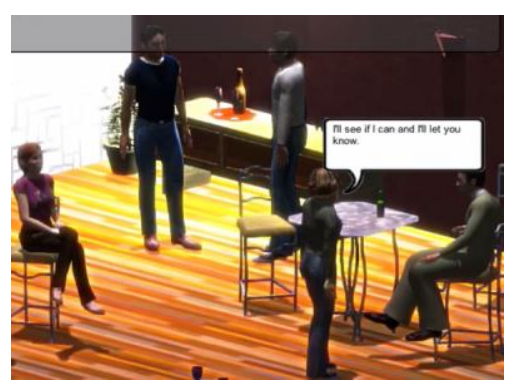

Figure 4. The body: third-person view with avatars in 3D, (C)Thomas Makryniotis.

\begin{tabular}{|c|c|c|c|c|c|}
\hline Case studies & $\begin{array}{c}\text { Digital Performance } \\
\text { (CCDP) }\end{array}$ & $\begin{array}{l}\text { Digital Fashion } \\
\text { (FDS-LCF) }\end{array}$ & $\begin{array}{c}\text { Information } \\
\text { Experience Design } \\
\text { (IED) }\end{array}$ & $\begin{array}{l}\text { Embodiment and } \\
\text { Learning (IOE-LKL) }\end{array}$ & $\begin{array}{c}\text { Psychology and } \\
\text { Development (IOE- } \\
\text { CoGDeV) }\end{array}$ \\
\hline $\begin{array}{l}\text { Available } \\
\text { Research } \\
\text { methods }\end{array}$ & $\begin{array}{l}\text { Practice-based } \\
\text { research, Artistic and } \\
\text { critical analysis, } \\
\text { Ethnography, } \\
\text { Philosophical and } \\
\text { material culture } \\
\text { methods, Audience } \\
\text { studies }\end{array}$ & $\begin{array}{c}\text { Design Methods, } \\
\text { Critical Design } \\
\text { Methods, Speculative } \\
\text { Design, User Centred } \\
\text { Design and Usability } \\
\text { Studies, Participatory } \\
\text { design }\end{array}$ & $\begin{array}{c}\text { Visual ethnography, } \\
\text { Digital curation, } \\
\text { Visualisation (2D/3D), } \\
\text { Cultural probes, } \\
\text { Experience } \\
\text { prototyping, Practice- } \\
\text { based research, } \\
\text { Hacking, making and } \\
\text { breaking, Critical } \\
\text { Design }\end{array}$ & $\begin{array}{c}\text { Interactional analysis, } \\
\text { Cognitive analysis, } \\
\text { Multimodality, } \\
\text { Interviews, } \\
\text { Observation, Video, } \\
\text { Participant drawing, } \\
\text { Quai-experimental } \\
\text { techniques }\end{array}$ & $\begin{array}{l}\text { Statistical analysis, } \\
\text { Visualisation (2D) }\end{array}$ \\
\hline $\begin{array}{l}\text { Routine Use of } \\
\text { Technologies }\end{array}$ & $\begin{array}{c}\text { Motion capture, } \\
\text { Programmable } \\
\text { interactive 3D digital } \\
\text { environments (e.g. } \\
\text { Isadora), Robotics, } \\
\text { Interactive wearables }\end{array}$ & $\begin{array}{l}\text { 3D-printers (plaster, } \\
\text { resin), Body, hand } \\
\text { and foot scanners, } \\
\text { Virtual garment } \\
\text { prototyping }\end{array}$ & $\begin{array}{c}\text { Mobile and GIS, } \\
\text { Sensor/actuator } \\
\text { technologies, 3D- } \\
\text { printers (wax, resin, } \\
\text { paper) }\end{array}$ & $\begin{array}{c}\text { Tangible } \\
\text { technologies, Mobile } \\
\text { and Geographical } \\
\text { Information Systems, } \\
\text { Sensor/actuator } \\
\text { technologies }\end{array}$ & $\begin{array}{c}\text { 3D virtual } \\
\text { environments, } \\
\text { Statistical packages }\end{array}$ \\
\hline $\begin{array}{c}\text { Observed } \\
\text { Events (Phase } \\
\text { I) }\end{array}$ & $\begin{array}{l}\text { Lectures on research } \\
\text { methods, Group and } \\
\text { individual rehearsals, } \\
\text { Workshops, } \\
\text { Performances }\end{array}$ & $\begin{array}{l}\text { Lectures on research } \\
\text { methods, Technical } \\
\text { demonstrations, } \\
\text { Workshops, Students' } \\
\text { presentations, } \\
\text { Fashion events }\end{array}$ & $\begin{array}{l}\text { Lectures on research } \\
\text { methods, Students' } \\
\text { presentations, } \\
\text { Departmental } \\
\text { meetings, Workshops, } \\
\text { Art exhibition events }\end{array}$ & $\begin{array}{c}\text { Group meetings, } \\
\text { Researchers' } \\
\text { presentations, } \\
\text { Research projects } \\
\text { meetings, Procedures } \\
\text { of data collection and } \\
\text { analysis }\end{array}$ & $\begin{array}{c}\text { Lectures on research } \\
\text { methods, } \\
\text { Departmental } \\
\text { meetings, Group } \\
\text { meetings, Procedures } \\
\text { of data collection and } \\
\text { analysis }\end{array}$ \\
\hline
\end{tabular}

Table 1. Case studies by methods, technologies and observed events.

with virtual environments for understanding route learning under different conditions [6]. The

'disembodied' character of the virtual environments being worked with, combined with the methods used are of particular interest to MIDAS.

\section{Conceptualising the body}

Across the case studies, there are differences in how the body is conceptualised in terms of interaction, environments, viewpoints, and interfaces, which in turn affects the methods used. In the social science sites, the emphasis is on the use of technology to augment the body, and the use of methods that help to capture this body augmentation. For example, the IOE-LKL project uses iPads GPS capabilities to connect the physical movement of the body in space with the movement of a dot on a 2D digital map, a body that is abstracted, situated, placed, and contextualized using a third-person view (Figure 2) and captured as GPS tracking data. In the IOE-CoGDeV project the body is 


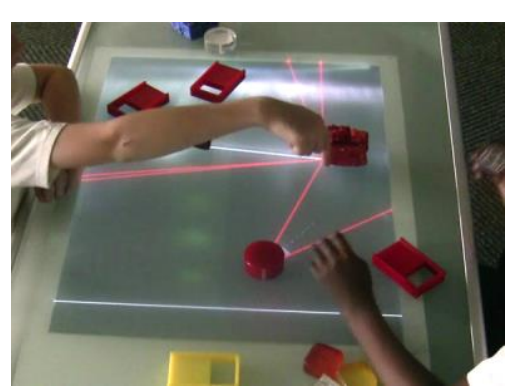

Figure 5. The sensory: touching visible light.

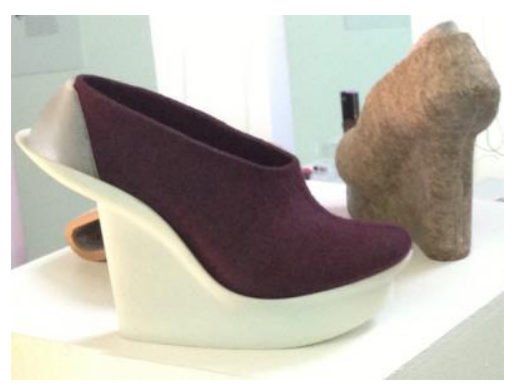

Figure 6. The sensory: materiality and 3D printing, @Liz Ciokajlo. deconstructed and absent in an experimental context, the body is situated in a 3D virtual environment of a maze using a first-person view controlled by a mouse device (Figure 3), and data is captured using system log files. There is a lack of connection between the movement within the maze, and the movement of the physical body. In the digital arts research sites we also find an exploration related to the augmented body with a critical approach to what and how are the boundaries between body and technology. For instance, in FDSLCF, a 3D game of fashion and social interaction developed by the fashion designer Makryniotis represents the body digitally using a third-person view with avatars, stressing the symbolic connotations of what you wear, with a lack of connection to the physical body, and connected to critical design methods (Figure 4). In the 5 case studies, moving from the physical to the virtual/digital back to the physical seems to be a key aspect of how the body is engaged with through the digital. What are the methodological implications of using different viewpoints and how to re-think methods for understanding situations with varied digital representations of the body are questions of interest to MIDAS.

The body features in and is represented differently across the sites, with some focusing on the whole body, others as a fragmented entity, others understanding the body as one part of a larger landscape. Similarly the lines drawn, blurred or removed between notions of the body and the mind vary. These differences reflect different purposes, and interests that circulate within the case study contexts - and these histories shape and inform their methodological practices.

Understanding the sociological and cultural underpinnings of these practices helps to inform how these methods may or may not be used and combined across the arts and social sciences.

Examining methods for researching the body across these five distinctive sites will, we envisage, highlight the implications of the different methodological views; provide new ways of conceptualising the body and points of synergy; and enable MIDAS to exploit these to develop novel methodological approaches.

\section{The sensory}

Nonverbal communication and what it means to experience the digital is an emergent theme across the case studies. In the social sciences sites, vision is a predominant mode of interaction, yet complemented by more senses. For example, a tangible tabletop system supports exploring concepts of the physics of light facilitating embodied interaction (Figure 5): whole body interaction led by the visual and touch senses, where the digital is sensed as a multimodal experience (e.g. touching properties of visible light using tangibles) and studied using video and multimodality. In the digital arts sites, the multisensory (e.g. touch, visual, hearing, or kinaesthetic) is researched in and through practice, with some methods 'borrowed' from social sciences (e.g., sensory ethnography, material anthropology). In FDS-LCF, Liz Ciokajlo's work on footwear design raises multisensory dimensions in relation to the materiality, textural character of the shoe using digital technologies (Figure 6). Digitally made materials are key for thinking and re-imagining the body - its boundaries and potentials. How to assess the multisensory in these different contexts is a topic of interest to MIDAS. 


\section{Discussion and conclusion: MIDAS and HCI}

This research aims to contribute to the development of a unified methodological framework to understand embodiment in HCI. We presented two initial themes which illustrate how we need to consider factors such as situation, context, place, environment, social interaction, or viewpoints; and to re-think innovative methods for understanding bodily and multisensory interaction. Current challenges include exploring the methodological implications of our emerging themes

\section{Acknowledgements}

This research is supported by ESRC. We thank the project Co-Is Douglas Atkinson, Susan Broadhurst and Kevin Walker; colleagues, collaborators and participants especially Emily Farran, Mona Sakr and Anna Waring.

\section{References}

[1] Atkinson, D., Orzechowski, P., Petreca, B., BianchiBerthouze, N., Watkins, P., Baurley, S., Padilla, S. and Chantler, M. Tactile perceptions of digital textiles: a design research approach. In Proc. CHI '13, ACM Press (2013), 1669-1678.

[2] Bødker, S. When second wave HCI meets third wave challenges. In Proc. NordiCHI '06, ACM Press (2006), 1-8.

[3] Broadhurst, S. Digital Practices: An aesthetic and neuroesthetic approach to virtuality and embodiment. Performance Research: A Journal of the Performing Arts, 11:4 (2011), 137-147.

[4] Buxton, B. Artists and the art of the luthier. ACM SIGGRAPH Computer Graphics, 31(1) (1997), 10-11.

[5] Dourish, P. Where the Action Is: The Foundations of Embodied Interaction. MIT Press (2001), Cambridge.

[6] Farran, E., Courbois, Y., Herwegen, J. V., and Blades, M. How useful are landmarks when learning a and the potential benefits to the HCI community. PostWIMP interfaces involve social interaction and complex interactions at the most difficult level of design, envisioned by [4] as the "artist spec". This interdisciplinary perspective is gathering up innovative methods for supporting our understanding of interaction and embodiment in $\mathrm{HCI}$, and will experiment with how these can inform a methodological framework that can be applied across the arts and social sciences.

route in a virtual environment? Evidence from typica development and Williams syndrome. Journal of Experimental Child Psychology, 111 (2012), 571-586.

[7] Harrison, S, Tatar, D. \& Sengers, P. alt.chi: The three paradigms of $\mathrm{HCI}$. In Proc. $\mathrm{CHI}$ '07, ACM Press (2007).

[8] Hutchins, E. Cognition in the Wild. MIT Press (1995), Cambridge, MA.

[9] Jacob, R.J.K., Girouard, A., Hirshfield, L.M., Horn, M.S., Shaer, O., Solovey, E. and Zigelbaum, J. Realitybased interaction: a framework for post-WIMP interfaces. In Proc. CHI '08 ACM Press (2008) 201-210.

[10] Jewitt, C. Routledge Handbook of Multimodal Analysis. Routledge (2009), London.

[11] Kress, G. Multimodality. Routledge (2010), London.

[12] Lakoff, G., and Johnson, M. Philosophy in the flesh: the embodied mind and its challenge to western thought. Basic Books (1999), New York.

13] Marshall, P., Hornecker, E. Theories of Embodiment in HCI. In The SAGE Handbook of Digital Technology Research, C. Jewitt, S. Price, and B. Brown, Eds. Sage (2013), London.

[14] Walker, K. Design research and research design. Design Observer (3 Oct 2011). 